\title{
POLYPHENOL ANALYSIS OF ASAVAS AND ARISHTAS - AN IMPORTANT MARKER FOR STANDARDIZATION
}

\author{
P. A. DUA ${ }^{1 *}$, S. D. PATANKAR ${ }^{2}$ \\ 1.*Ph.D.Scholar, Dept. of Microbiology, Sardar Patel Mahavidyalaya, Chandrapur. \\ 2. Ex-Principal, S.S. Jaiswal College of Arts, Commerce and Science, Arjuni Mor. \\ email id-jeevanrenu@gmail.com, email id - duaprachi@gmail.com
}

\begin{abstract}
:
Ayurveda has gained worldwide attention due to its efficacy. Ayurvedic medicines are formulated from medicinal plants using modern scientific techniques. Standardization of these prepared medicines plays a very crucial role for their authentication. As the need for safer drugs is increasing, an awareness has been drawn to the quality and standards of the ayurvedic formulations. As these formulations are based on plant materials, it is rich in phytochemicals. The main aim of the present work was to quantify different polyphenols present in the samples of Lohasava, Punnarnavasa, Amritarishta and Kirayatikadha. The polyphenols identified by RP-HPLC could be used as phytochemical analytical markers for these formulations. These findings can certainly help in the quality assurance during the manufacturing of the given formulations.
\end{abstract}

Keywords: Polyphenols, asavas, arishtas, fermentation, biotransformation.

\section{INTRODUCTION:}

Ayurvedic system of medicine is accepted as the oldest written medical system that came into existence in about 900 B.C.; which is more effective in some cases than in modern therapies (Jerald EE, 2007). A variety of ayurvedic medicines are available in order to meet the diverse requirement in the treatment of human illness (Sekar \& Mariappan, 2008). Asavas are medical preparations made by soaking the drugs in coarse powder form, in a solution of jaggery or sugar as cited in he literature, for a specified period of time during which it undergoes a process of fermentation thereby leading to production of alcohol; which facilitates extraction of active principles contained in the drugs. The alcohol, thus generated also acts as a preservative (The Ayurvedic Pharmacopoeia of India). Arishtas, are however fermented decoctions. According to a report of WHO nearly $80 \%$ of the earth's population rely on traditional medicines for their primary health care needs. The therapyfor treatment involves using the plant extracts or their active components (Kalaiselvan et al, 2010). These active components are the phytochemicals. One amongst them is polyphenols which may or may not be affected during the course of fermentation.

Polyphenols are the natural compounds found mainly in fruits, vegetables, cereals and beverages (Spencer et al, 2008). Polyphenols are the source of antioxidants in our diet. Since the average daily intake is about $1 \mathrm{~g}$ which is almost 10 fold intake of vitamin C; 100 fold intake of vitamin E and 500 fold intake of carotenoids (Scalbert et al, 2000; 2005). Polyphenols are secondary metabolites of plants and protects the plants by aiding in defence against UV radiation or aggression by pathogens (Beckman, 2000). Apart from their antioxidant properties, polyphenols show some other biological activities including antimutagenic, anti-oestrogenic, anticarcinogenic and anti-inflammatory effects that might potentially be beneficial in human health such as in treatment and prevention of cancer, cardiovascular diseases and other pathologies (Bravo, 1998). There is a clear evidence that they have the potential to act in three general areas specified i.e. transition metal ion complexation, as antioxidants in cellular pro - oxidant states, and by 
association with proteins and peptides (Haslam, 1996). Almost all polyphenols possess antioxidant property and hence are responsible for their purported beneficial health effects associated with conditions such as cancer, cardiovascular diseases, neurodegenerative diseases and aging (Manach et al, 2004). Whereas several issues related to disease protective activities of polyphenols are still unsolved. One of the burning issues is bioavailability of these polyphenols, since it plays important role in evaluating the efficiency as well as efficacy of these compounds (Kanti Bhooshan Pandey, 2009). As these polyphenols are responsible for the therapeutic action of specific formulation, they can be used as an analytical marker for the standardization of the formulation.

An attempt was thus made in the present study to analyze the different polyphenols present initially and after the process of fermentation in the final product. For this, two asavas namely Punarnavasava and Lohasava were chosen. On the other hand, two arishtas chosen were Amritarishtha and Kirayatikadha.

\section{METHOD AND MATERIAL:}

Chemicals and Reagents - Methanol (HPLC grade), Acetone (GR), Sodium dihydrogen phosphate dihydrate $\left(\mathrm{Na}_{2} \mathrm{H}_{2} \mathrm{Po}_{4} .2 \mathrm{H}_{2} \mathrm{O}\right)$, Sodium Carbonate $\left(\mathrm{Na}_{2} \mathrm{Co}_{3}\right)$, Folin - Ciocalteu (F-C), Dimethyl sulfoxide (DMSO) Reagent were highest analytical grade and purchased from Merck. Reference compounds for HPLC were from Extrasynthase and Sigma Aldrich.

Samples - The samples were collected from the manufacturing unit directly after regular time intervals Oday, after 10 days, 20 days and after 30 days i.e. completion of fermentation. The samples were stored in the refrigerator till the processing was done. The samples were shaken properly and used. Fixed amount of sample was taken and were extracted in extraction solution $25 \mathrm{ml}$ two times. The extracted sample was vortexed and centrifuged at 7000rpm for 10 minutes, the supernatant was collected and this is known as the raw extract. The raw extracts were evaporated using rotary evaporator (B'U'CHI, R-215, made in Switzerland) and the samples were reconstituted with $5 \mathrm{ml}$ and $10 \mathrm{ml}$ of DMSO. The extracts were centrifuged at 4200rpm for 10 minutes and filtered through a Whatman $0.2 \mu \mathrm{m}$ syringe filter (PTFE) before analysis.

HPLC analysis for characterization of the phenolics in samples was detected by using the following individual standards namely Gallic acid, Gallocatechin, Protocatechuic acid, 3,4-Dihydroxy benzoic acid, Epigallocatechin, Chlorogenic acid, Catechin, Syringic acid, Vanillic Acid, 3-OH Benzoic acid, Epicatechin, Caffeic acid, Sinapic acid, (Catechin gallate, Procyanidin B2, Epigallocatechin gallate, Ferulic acid, Isoferulic aicd,4-Coumaric aicd, Hesperdien, Gallocatechin gallate, Epicatechin galate, 2-Coumaric acid, Rosmaric acid, Isovitexin,Luteolin-7-O-Glucoside, Hespertin, Quercetin -3-Beta-Galactoside,Hyperoside,Ellagic acid, Rutin, Physcion, Daidzein, Galangin, Salicyclic acid, Rhoifolin, Naringenin, Flavonone(internal standard), Quercetin, Luteolin, Chrysophanol, Chalcone, Rhein, Isorhamnetin, Myricetin, Emodin, Kaempferol, Cinnamic aicd and Curcumin. Calibration curves were made by diluting stock solutions with DMSO to give concentration of the standard in the range $1 \mathrm{mg} / 1 \mathrm{ml}$ for standards. The calibration curves were constructed from chromatograms as peak area vs. concentration of standard. Linear calibration curves were obtained with all phenolic standards within the concentration range studied $(r=0.9992-0.9999)$. The limits of detections (LOD) were calculated from the parameters obtained from calibration curves, using the formula LOD $=3.3 \mathrm{Sa} / \mathrm{b}$, where $\mathrm{Sa}$ is the standard deviation of the $y$-intercept of the regression line and $\mathrm{b}$ is the slope of the calibration curve (Ribani et al, 2007). 
The HPLC system employed was a Dionex HPLC series Ultimate 3000 (Germany) equipped with Dionex model Chromeleon software, autosampler U3000 , and 3000 RS diode array detection system to monitor at all wavelengths from 200 to 600nm. For the column, Dionox PA 2 RSLC 120 A, Column $\mathrm{C}_{18}$ Acclaim RSLC, (100mm x 2.1dm) i.e., $2.1 \mu$ Thermo Scientific Ltd was used at $35{ }^{\circ} \mathrm{C}$. Gradient elution was performed with solution A, composed of $50 \mathrm{mM}$ Sodium phosphate $(\mathrm{pH} 3.3)$ and 10\% methanol, and solution B, comprising of $70 \%$ methanol, delivered at a flow rate of $0.47 \mathrm{ml} / \mathrm{min}$ as follows: initially $100 \%$ of Solution A; for the next $0.03 \mathrm{~min}, 70 \% \mathrm{~A}$; for another $2.65 \mathrm{~min}, 65 \% \mathrm{~A}$; for another $7.9 \mathrm{~min}$, $60 \% \mathrm{~A}$; for another $11.5 \mathrm{~min} 50 \% \mathrm{~A}$ and finally $0 \% \mathrm{~A}$ for $13.1 \mathrm{~min}$, again $17 \mathrm{~min} 100 \% \mathrm{~A}$ and $20.25 \mathrm{~min}$ $100 \%$ A. The injection volume of the extract was $5 \mu 1$ (Sakakibara et al, 2003).

\section{RESULTS AND DISCUSSION}

The asavas and arishtas were prepared by the process of fermentation as stated in the literature and RP-HPLC analysis was carried out of the non fermented sample as also of the samples withdrawn after specific time intervals till the completion of the fermentation process. The elution of standard polyphenols on HPLC showed the above chromatogram. The results obtained were tabulated as given in the table 1 and table 2 .

It was determined that during the process of fermentation significant chemical change was observed in the quantity of polyphenols. Thus the fermentation resulted in considerable changes in the quality and quantity of both high and low molecular weight phenolic compounds which modify the biological activity of the fermented extracts, particularly fermented biomedicines like asavas and arishtas (Gill et al, 2018). This modified activity could be responsible for the therapeutic action of these medicines.
The polyphenol concentration decreased in the biomedicines after fermentation with few exceptions. Similar observations were made for bean polyphenols by Cuellar Alvarez and Zapata et al (2013). In Amritarishta, the concentration of polyphenols decreased with the exception of chlorogenic acid whose concentration increased significantly from $1.765 \mathrm{mg} / 100 \mathrm{~g}$ to $6.436 \mathrm{mg} / 100 \mathrm{~g}$, lutelion-7-O-glucose which was initially not detected increased to a concentration of $0.044 \mathrm{mg} / 100 \mathrm{~g}$. This polyphenol has been used as a marker polyphenol in Amritarishta by Wadkar et al. In Lohasava, the concentration increased from $0.358 \mathrm{mg}$ to $0.693 \mathrm{mg}$ for vanillic acid, from $0.350 \mathrm{mg}$ to $0.724 \mathrm{mg}$ for $\mathrm{OH}$-benzaldehyde and from $6.738 \mathrm{mg}$ to $0.794 \mathrm{mg}$ for chlorogenic acid. For Punnarnavasava, the polyphenols like kaemperferol, lutelion-7-O-glucose, vanillic acid, chlorogenic acid, caffeic acid were initially not in the detectable range. However, their concentration reached to $0.076 \mathrm{mg}, 0.062 \mathrm{mg}, 2.326 \mathrm{mg}, 5.781 \mathrm{mg}$ and $0.437 \mathrm{mg}$ respectively. Ferulic acid which initially had a concentration of $0.089 \mathrm{mg}$ reached a value of $1.755 \mathrm{mg} / 100 \mathrm{~g}$. Exceptionally for Kirayatikadha, all the polyphenols which were present initially showed an increase in concentration.

Basically fermentation is a microbiological process which occurs spontaneously and results into biochemical changes. The micro organisms are activated by the temperature changes during the fermentation process (Yader et al, 2014). The concentration of most of the polyphenols is lower in fermented sample as compared to the non fermented sample. This is due to the liquid reduction caused by the fermentation process (Wollgast \& Anklam, 2000). Another mechanism of polyphenol loss is the action of polyphenol oxidase enzyme E.C.1.14.18.1, which is responsible for catalyzing the polyphenol oxidation to high 
molecular weight condensed polyphenol (Weisberger, 2001).

The polyphenols are present in foods in the form of esters, glycosides or polymers that cannot be absorbed in the native form. Therefore these substances must be hydrolyzed by enzymes present in the gut such as $\beta$-glucosidases and lactase-phlorizin hydrolase or by the colonic microflora, before they can be absorbed (Nemeth, 2003). A reduction in the concentration of specific polyphenol indicates their hydrolysis or oxidation and conversion into simpler forms which could be better absorbed. Similar observations were made in rats by Carbonaro et al. According to Skrabanja V, polyphenol may be bound in protein polyphenol complexes are modified by enzymes i.e. some biotransformations are taking place by the microbes present during fermentation.

According to literature, before carrying out the process of fermentation soaking of some components is to be done. There might be loss of some tannins during the soaking of components. The reason for their loss can be attributed to their dominant presence in the seed coat and also as they are water soluble, readily leach out into the liquid medium (Reddy \& Pierson, 1994; Kumar et al, 1979). A decrease in the concentration of polyphenols may be due to improper storage conditions. Storage is a factor that affects the content of polyphenols that are easily oxidized. Oxidation results in the formation of more or less polymerized substances which leads to changes in quality of foods particularly in colour and organoleptic characteristics (Sosulski, 1982).

\section{CONCLUSION}

Based on surveys, the use of traditional medicines from medicinal plants and plant products is apparently increasing throughout the world in the treatment of diseases and also for healthy life. Use of traditional medicines is widespread in many countries. In India, about $40 \%$ of the total medicinal consumption is attributed to traditional tribal medicines.

Most of the research studies have confirmed that the natural polyphenols are responsible for the beneficial effects of herbal medicines. A protective role of polyphenols against degenerative diseases is supported today by many studies carried out on humans and different mechanisms of action have been proposed to explain such protective efforts. However, study on polyphenols is quite complex because of heterogeneity of different molecular structures and scarcity of data on bioavailability and biotransformation. An attempt was made in the present study to find out the active polyphenols in some asavas and arishtas and their fate during the course of fermentation. Some of these polyphenols could be used as analytical markers for these medicines. However, there is need for more research and development so as to find out the biotransformation of the polyphenols to exactly determine the role of these bioactive compounds with respect to human health.

\section{ACKNOWLEDGEMENT:}

Thanks to the Department of Science and Technology, New Delhi for the financial support. Thanks to National Institute of Nutrition, Hyderabad for providing help and facilities for carrying out the RP-HPLC analysis. Authors are also grateful to S. P. College, Chandrapur for providing the necessary facilities to carry out the study.

\section{REFERANCE:}

Beckman CH. Phenolic Storing Cells, keys to programmed cell death and periderm formation in wilt disease resistance and in general defence responses in plants. Physiol Mol Plant Pathol. 2000; 57:101-110. 
Bravo L. Polyphenols: Chemistry, dietary sources, metabolism and nutritional significance. Nutr Rev. 1998; 56(11): 317-333.

Carbonaro M, Grant G, Pusztai A. Evaluation of polyphenol bioavailability in rat small intestine. Eur J Nutr. 2001; 40(2): 84-90.

Haslam E. Natural Polyphenols (vegetable tannins) as rugs: possible modes of action. J. Nat. Prod. 1996; 59(2): 205-215.

Jerald EE. Textbook of Pharmacognosy and Phytochemistry. CBS Publication, New Delhi, 2007, pp. 8-62.

Kalaiselvan V, Shah AK, Patal FB, Shah CN, Kalaivani M. Quality Assessment of Different Marketed brands of Dashmoolarishtam- an Ayurvedic formulation. Int $\mathrm{J}$ of Ayur Res. 2010; 1: 10-13.

Kanti Bhooshan Pandey, Syed Ibrahim Rizvi. Current Understanding of Dietary Polyphenols and their Role in Health and Disease. Current Nutrition and Food Science. 2009;(5): 249-263.

Kumar NR, Reddy AN, Rao KN. Levels of phenolic substances on the leachionted in cicezo seed. Journal of Experimental Biology. 1979; 17:114 -116 .

Manach C, Scalbert A, Morand C, Remsey C, Jimenez L. Polyphenols: food sources and bioavailability. Am J Clin Nutr. 2004; 79:727747.

Nemeth K, Plumb GW, Berrin JG et al. Deglycosilation by small intestinal epithelial cell beta- glucosidases is a critical step in the absorption and metabolism of dietary flavonoid glycosides in humans. Eur J Nutr. 2003; 42: 29-42.

Reddy NR, Pierson MD. Reduction in antinutritional and toxic components in plant foods by fermentation. Food Res Int. 1994; 27: 281-290.

Ribani M, Collins CH, Bottoli CBG. Validation of chromatographic methods: Evaluation of detection and quantification limits in the determination of impurities in omeprazole.
Journal of Chromatography. 2007; 1156: 201205.

Sakakibara H, Honda Y, Nakagawa S, Ashida H, Kanazawa, K. Simultaneous Determination of all Polyphenols in Vegetables, Fruits and Teas. Journal of Agricultural and Food Chemistry. 2003; 51: 571 - 581.

Scalbert A, \& Williamson G. Dietary intake and bioavailability of polyphenols. J. Nutr. 2000; 130:20735 - 20855.

Scalbert A, Johnson LT \& Saltmarsh M. Polyphenols - Antioxidants and Beyond. American Journal of Clinical Nutrition. 2005; 81(suppl): 215S-7S.

Sekar S, Mariappan S. Traditionally Fermented Biomedicines - Arishtas and Asavas from Ayurveda. Ind J Traditional Knowledge. 2008; $7(4): 548-56$.

Skrabanja V, Laerke HN, Kreft I. Protein polyphenol interactions and invivo digestibility of buckgoat proteins. Pflugers Archiv: European Journal of Physiology. 2000; 440(5Suppl): R129 -R131.

Sosulski F, Krygier K, Hoggle L. Free, esterified and insoluble bound phenolic acids 3. Composition of phenolic acids in cereals and potato flours. $J$ Agric Food Chem. 1982; 30: 337-40.

Spencer JP, Abd El Mohsen MM, Minihane AM, Mathers JC. Biomarkers of the intake of dietary polyphenols: Strengths, Limitations and Applications in Nutrient Research. Br. J. Nutr. 2008; 99: 12-22.

The Ayurvedic Pharmacopoeia of India, First edition, Vol. II, Part II, Controller of Publications, Civil Lines, Delhi.

Wadkar KA, Kondawar MS, Lokapure SG. Standardization of marketed Amritarishta - a herbal formulation. Int $\mathrm{J}$ of Pharmacogn. 2016; 3(9): 392-399.

Weisberger JH. Chemopreventive effects of cocoa polyphenols on chronic diseases. Exp Biol Med. 2001; 226(10): 891-897.

Wollgast J, Anklam E. Review on polyphenols in Theobroma cacao: changes in composition 
during the manufacture of chocolate and methodology for identification and quantification. Food Res Int. 2000; 33(6): 423447.

Yader Suazo, Gabriel Davidov- Pardo, Inigo Arozarena. Effect of fermentation and roasting on the phenolic concentration and antioxidant activity of cocoa from Nicargua. J Food Chem. 2014; Vol 37.

Zapata Bustamante S, Tamaya Tenorio A \& Alberto Rojano B. Efecto de le fermentacion sobre la actividad antioxidante de diferentes clones de Colombiano. Revista Cubana de Plantas Medicinales. 2013; 18(3): 391-404.

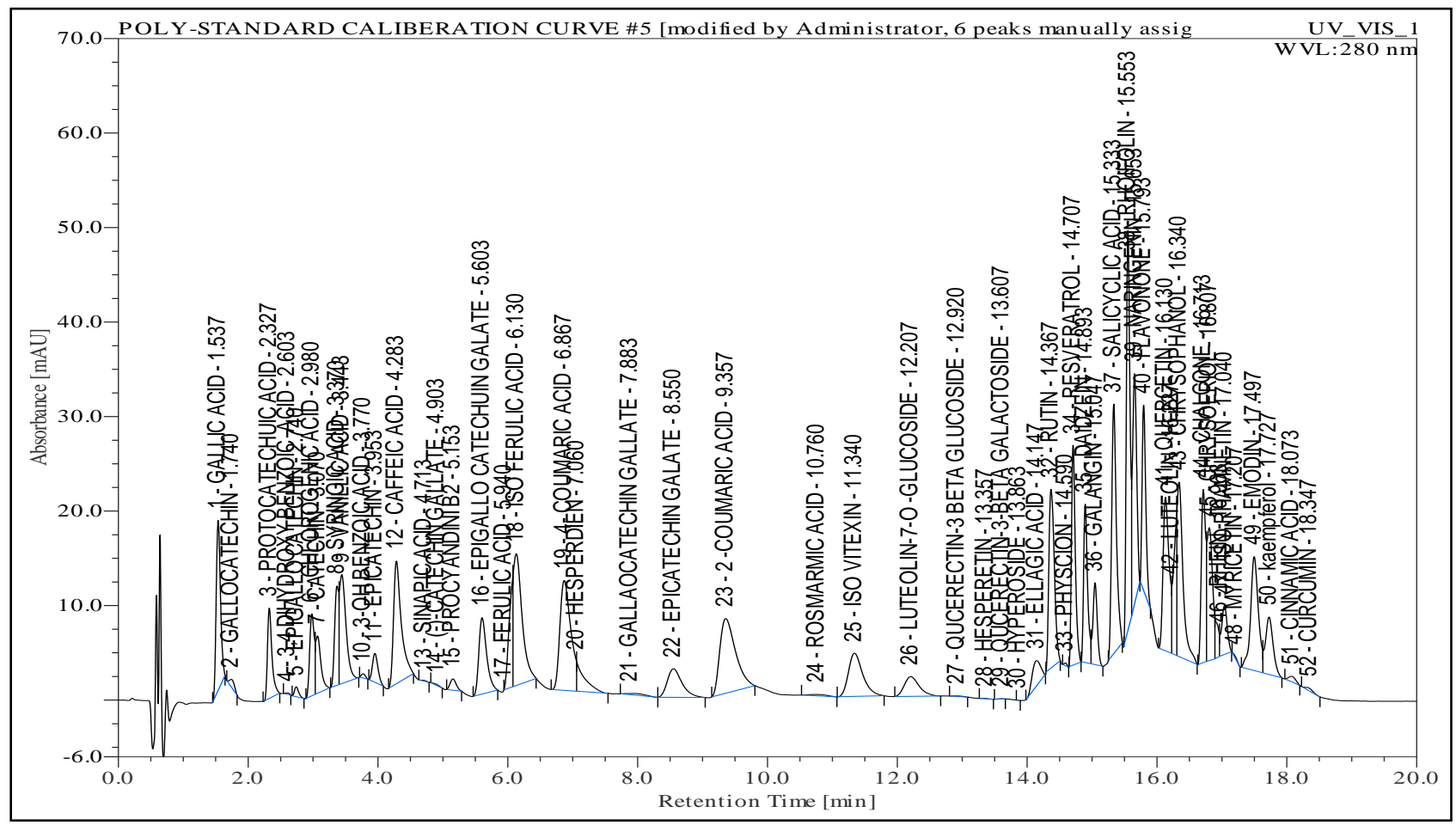

Fig.. HPLC ANALYSIS CHROMATOGRAM: ELUTION PROFILE OF A STANDARD MIXTURE OF POLYPHENOLS 
Table 1 - Polyphenol concentration (mg/100g sample) in different samples

\begin{tabular}{|c|c|c|c|c|c|c|c|}
\hline \multirow[t]{2}{*}{ SAMPLE } & GALLIC & PROTOCATECHUIC & VANILLIC & OH- & CHLOROGENIC & CAFFEIC & FERULIC \\
\hline & ACID & ACID & ACID & BENZALDEHYDE & ACID & ACID & ACID \\
\hline A1 & ND & $1.601 \pm 0.003$ & $2.217 \pm 0.008$ & $0.36 \pm 0.007$ & $1.765 \pm 0.006$ & $1.813 \pm 0.006$ & $\begin{array}{c}1.966 \pm \\
0.006\end{array}$ \\
\hline $\mathrm{A} 2$ & ND & $0.613+0.004$ & $1.514+0.007$ & $0.348+0.007$ & $3.701+0.008$ & $0.795+0.005$ & $\begin{array}{c}0.034 \pm \\
0.005 \\
\end{array}$ \\
\hline A3 & ND & $0.387+0.004$ & $0.314+0.003$ & $0.195 \pm 0.005$ & $5.312+0.005$ & $0.422+0.007$ & ND \\
\hline A4 & ND & $0.218 \pm 0.005$ & ND & ND & $6.435 \pm 0.005$ & $0.033 \pm 0.006$ & ND \\
\hline L1 & $\begin{array}{l}2.01 \pm \\
0.003\end{array}$ & $1.294+0.005$ & $0.357+0.006$ & $0.349+0.007$ & $6.737+0.006$ & $2.741+0.004$ & $\begin{array}{c}0.352 \pm \\
0.007\end{array}$ \\
\hline L2 & $\begin{array}{c}0.463 \pm \\
0.008\end{array}$ & ND & $1.606+0.006$ & $0.388+0.006$ & $8.874+0.005$ & $0.723+0.006$ & $\begin{array}{c}0.332 \pm \\
0.005\end{array}$ \\
\hline L3 & $\begin{array}{c}0.374 \pm \\
0.003\end{array}$ & ND & $1.867 \pm 0.006$ & $0.409 \pm 0.007$ & $7.382+0.005$ & $0.357 \pm 0.006$ & $\begin{array}{c}0.035 \pm \\
0.007\end{array}$ \\
\hline L4 & $\begin{array}{l}0.33 \pm \\
0.006\end{array}$ & ND & $0.691+0.009$ & $0.724+0.005$ & $7.974+0.005$ & $0.343+0.006$ & ND \\
\hline $\mathrm{P} 1$ & $\begin{array}{c}0.917 \pm \\
0.003\end{array}$ & ND & ND & ND & ND & ND & $\begin{array}{c}0.088 \pm \\
0.006\end{array}$ \\
\hline $\mathrm{P} 2$ & $\begin{array}{c}0.525 \pm \\
0.007\end{array}$ & ND & $0.676+0.006$ & ND & $4.549+0.004$ & $0.074+0.007$ & $\begin{array}{c}0.327 \pm \\
0.006\end{array}$ \\
\hline P3 & $\begin{array}{c}0.682 \pm \\
0.004\end{array}$ & ND & $3.06 \pm 0.008$ & $0.274 \pm 0.008$ & $7.404 \pm 0.006$ & $1.354 \pm 0.006$ & $\begin{array}{c}0.767 \pm \\
0.006\end{array}$ \\
\hline $\mathrm{P} 4$ & $\begin{array}{c}0.717 \pm \\
0.007\end{array}$ & ND & $2.326+0.006$ & ND & $5.783+0.006$ & $0.437 \pm 0.006$ & $\begin{array}{c}1.755 \pm \\
0.006\end{array}$ \\
\hline $\mathrm{K} 1$ & $\begin{array}{c}0.113 \pm \\
0.004\end{array}$ & $4.285 \pm 0.005$ & $0.238 \pm 0.007$ & ND & $13.042 \pm 0.006$ & $1.05 \pm 0.008$ & ND \\
\hline $\mathrm{K} 2$ & $\begin{array}{c}0.114 \pm \\
0.004\end{array}$ & $4.743+0.005$ & $0.452+0.007$ & ND & $13.54+0.005$ & $1.089+0.006$ & ND \\
\hline K3 & $\begin{array}{c}0.131 \pm \\
0.004\end{array}$ & $5.857 \pm 0.006$ & $0.839+0.007$ & ND & $17.482+0.006$ & $1.513+0.006$ & ND \\
\hline $\mathrm{K} 4$ & $\begin{array}{c}0.183 \pm \\
0.004\end{array}$ & $5.525 \pm 0.005$ & $1.432 \pm 0.007$ & ND & $16.952 \pm 0.007$ & $1.332 \pm 0.006$ & ND \\
\hline
\end{tabular}

Values are mean of three \pm S.D. 